\title{
Tautomerism in Pindone - A DFT Study
}

\section{Lemi Türker}

Department of Chemistry, Middle East Technical University, Üniversiteler, Eskişehir Yolu No: 1, 06800 Çankaya/Ankara, Turkey; e-mail: lturker@gmail.com; lturker@metu.edu.tr

\begin{abstract}
Pindone is a rodenticide having three keto groups in its structure. Presently, 1,3-type ketoenol tautomerism of pindone has been studied within the constraints of density functional theory at the level of B3LYP/6-311++G(d,p). Various structural and quantum chemical properties of these tautomers have been obtained, compared and discussed. Endocyclic and exocyclic enol forms of pindone are accompanied by dipole moment vectors having opposite directions. The endocyclic enol structure is found to be more stable than the exocyclic enol and pindone. IR and UV-VIS spectra are obtained. NICS $(0)$ values are calculated to visualize the effect of tautomerism on the local aromaticity of the structures considered.
\end{abstract}

\section{Introduction}

Pindone (2-Pivalyl-1,3-indandione) is a first generation anticoagulant rodenticide of the indandione type, as are chlorophacinone and diphacinone [1]. Anticoagulant rodenticides inhibit the vitamin $\mathrm{K}$ dependent step in the synthesis of a number of blood coagulation factors by blocking a liver enzyme responsible for the recycling of vitamin $\mathrm{K}$ $[1,2]$. The efficacy of first generation products such as warfarin (a first generation hydroxycoumarin) has been reduced by the development of resistance in some parts of the world, and they have largely been superseded by second generation anticoagulants of the hydroxycoumarin type, such as bromadiolone and brodifacoum. These newer compounds are lethal to target rodents after a single feed, although death is delayed for

Received: October 19, 2019; Accepted: December 8, 2019

Keywords and phrases: pindone, 2-pivalyl-1,3-indandione, tautomerism, DFT, NICS.

Copyright (C) 2020 Lemi Türker. This is an open access article distributed under the Creative Commons Attribution License, which permits unrestricted use, distribution, and reproduction in any medium, provided the original work is properly cited. 
some days. Baits containing the indandiones and the first generation hydroxycoumarins must generally be consumed repeatedly before death occurs.

Several substituted indandiones also interfere with blood coagulation. One of them is pindone which is prepared by condensation of diethyl phthalate and pinacolone.<smiles>CCOC(=O)c1ccccc1C(=O)OCC</smiles><smiles>CC(=O)C(C)(C)C</smiles>

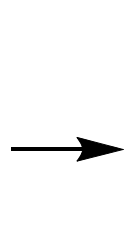<smiles>CC(C)(C)C(=O)C1C(=O)c2ccccc2C1=O</smiles>

There are currently two chemical forms of pindone; pindone acid (a mixture of keto and enol forms) and pindone sodium (sodium salt of pindone), which are used to prepare baits for rabbit control in Australia. The main difference between the two is that pindone acid has low water solubility while the sodium salt is soluble in water [1-5]. Based on the differences in water solubility it has been proposed, but not yet proven, that baits based on pindone acid will remain active for a longer period than baits based on pindone sodium. Acid and salt forms of pindone can be regarded as essentially equivalent in toxicity once ingested as gastric acidity liberates the "free acid" from the salt. Both forms of pindone break down to the same endproduct in the field and have the same nontarget impacts to fauna.

Pindone is a first generation anticoagulant used to control rabbits in areas where the alternative rabbit poison, sodium fluoroacetate, is either impractical or unsuitable. These include urban and semi-rural areas including hobby farms, golf courses and horticultural areas. Pindone inhibits the manufacture of blood clotting factors (prothrombin), leading to a reduction in the clotting ability of the blood. Large single exposures can result in acute poisoning, however, pindone is highly effective when given as a series of smaller doses over a period of 4 to 12 days. This causes anticoagulant poisoning with a long latent period between ingestion and mortality, resulting in death due to internal haemorrhaging. One of the advantages of pindone is the availability of an antidote in the case of accidental poisonings [6].

Pindone has a long history of use in Australia for control of rabbits. For example, the pindone acid form was introduced in Western Australia in 1984. Both pindone acid and pindone sodium products are registered in Australia for use as a vertebrate poison to 
control rabbits. They are generally used in urban and semi-urban situations where sodium fluoroacetate cannot be used. Sodium fluoroacetate is the widely used poison for rabbits because it is cheaper, and has the additional advantage particularly in Western Australia in that many native species have some tolerance to fluoroacetate. However, the lack of an antidote for this substance makes it unsuitable for use in and around urban areas where domestic animals may be exposed. Pindone is the only reversible poison available for rabbit baiting in such situations [2-5].

The structurally related indandiones, chlorophacinone and diphacinone have very similar properties to pindone. Crystal structure of pindone was determined [7]. On the other hand, the tautomerism in indandiones has attacked attention especially in the past [8-11].

\section{Method of Calculation}

Optimized geometries of all the structures leading to energy minima have been achieved by using MM2 method prior to semi-empirical PM3 self-consistent fields molecular orbital (SCF MO) method [12, 13] at the restricted level [14, 15]. The subsequent optimizations are achieved at Hartree-Fock level using various basis sets hierarchically. Finally, the structure optimizations were managed within the framework of density functional theory [16, 17], finally at the level of B3LYP /6-311++G(d,p) [14]. The exchange term of B3LYP consists of hybrid Hartree-Fock and local spin density (LSD) exchange functions with Becke's gradient correlation to LSD exchange [17, 18]. Note that the correlation term of B3LYP consists of the Vosko, Wilk, Nusair (VWN3) local correlation functional [19] and Lee, Yang, Parr (LYP) correlation correction functional [20]. Also, the vibrational analyses have been done for all the structures. The total electronic energies have been corrected for the zero point vibrational energy (ZPE). The stationary points to energy minima were proved in all the cases by calculating the second derivatives of energy with respect to the atom coordinates. The normal mode analysis for each structure yielded no imaginary frequencies for the $3 N-6$ vibrational degrees of freedom, where $N$ is the number of atoms in the system. This indicates that each structure corresponds to at least a local minimum on the potential energy surface. All these calculations were done by using the Spartan 06 package program [21]. The NICS (0) calculations were performed by using Gaussian 03 package program [22]. 


\section{Results and Discussion}

Pindone possesses three carbonyl groups (two of which are involved in cyclopentadione moiety) and all are connected to a common tertiary carbon atom which is also in the cyclopentadione skeleton. This structural peculiarity allows the possibility of two sets of enolization process via 1,3-tautomerization as shown below. The enol structures formed, P1 and P2, have endocyclic and exocyclic carbon-carbon double bonds, respectively. Since the cyclopentadione moiety is fused with phenylene system, in pindone, the enolization should affect the flow of electrons from the aromatic system to the carbonyls linked to it. The relative stabilities of tautomers P1 and P2 compared to each other as well as to pindone are a matter of interest. Also the variation of associated properties of these structures are of scientific interest. Note that as a rodenticide, the mode
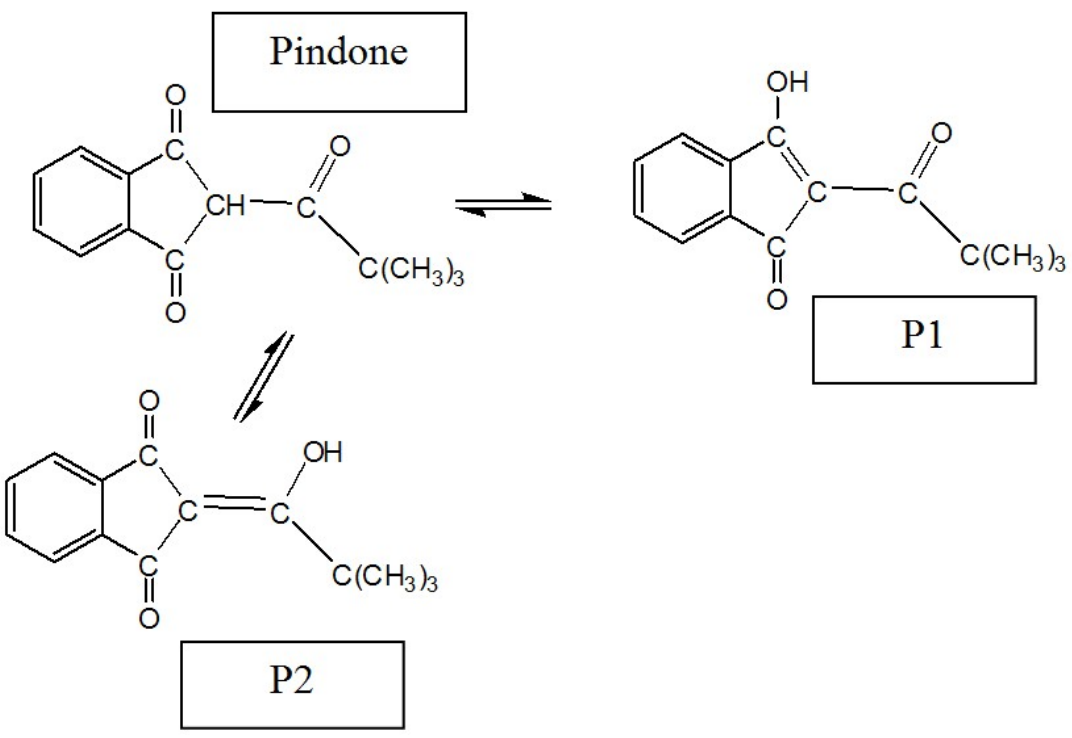

of action of pindone is based on its anticoagulant property. Although, warfarin, another rodenticide has been used successfully over decades, pindone can be used as a substitute for warfarin when rats become bait shy [1]. Both warfarin and pindone tautomer P1 have endocyclic enone structure as well as enol moieties, although warfarin has those groups associated with its coumarine backbone having six-membered rings.

Figure 1 shows the optimized structures as well as the direction of the dipole moment vectors of pindone and its 1,3-tautomers P1 and P2. As seen in the figure direction of the dipole moment vector in $\mathrm{P} 2$ has changed as compared to the other cases. 


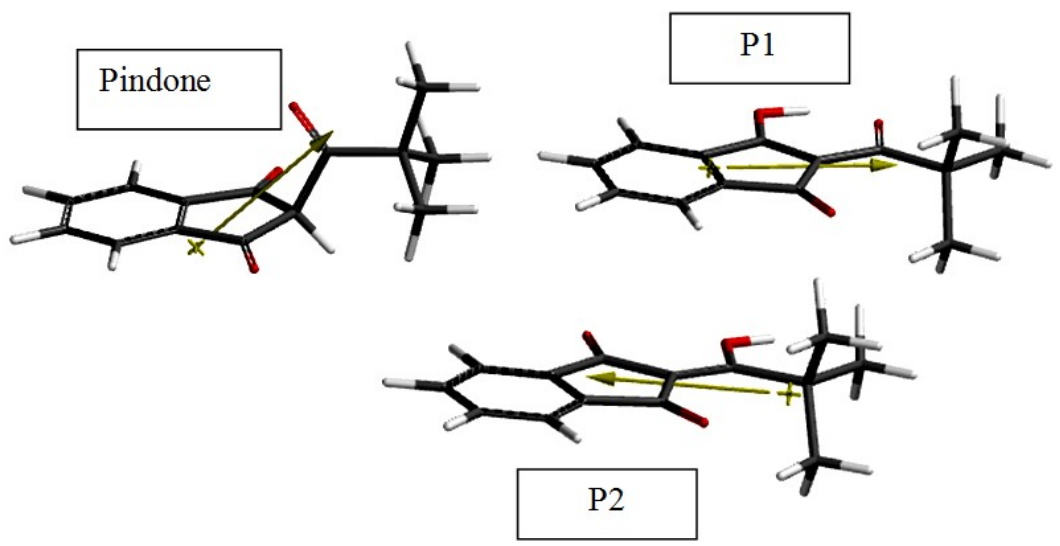

Figure 1. Optimized structures of pindone and its tautomers.

Note that the enolic double bond in P2 is exocyclic whereas in P1 it is endocyclic. In both cases the dipole moment vectors almost lie in the plane of the endo or exocyclic carbon-carbon double bond. In P1 carbonyl group of the substituent acts as an electron withdrawing moiety whereas in P2 cyclopentadione system fused with the phenylene moiety gets the role of an electron attracting group. Thus, the directions of dipole moment vectors in P1 and P2 are opposite to each other.

Table 1 shows some calculated properties of the species considered. The tautomers P1 and P2 possess comparable area and volume values but they are less than the respective values of pindone. The dipole moment order is $\mathrm{P} 1>$ pindone $>\mathrm{P} 2$ whereas the polarizabilities follow the order of pindone $>$ P1 $>$ P2. All these structural features dictate the $\log \mathrm{P}$ values displayed in the table.

Table 1. Some properties of the structures.

\begin{tabular}{lccc}
\hline & Structures & & \\
\hline & Pindone & P1 & P2 \\
Area $(\AA)^{2}$ & 259.00 & 250.10 & 250.77 \\
Volume $(\AA)^{3}$ & 241.06 & 239.01 & 239.58 \\
Ovality & 1.38 & 1.34 & 1.34 \\
Dipole moment (Debye) & 2.26 & 2.87 & 2.20 \\
Polarizability & 59.84 & 59.82 & 59.76 \\
Log P & 2.76 & 2.32 & 1.57 \\
\hline
\end{tabular}


Figure 2 shows the calculated bond lengths of the structures considered. As the result of enolization process, the bonds involved in the process are subjected to certain changes, for instance $\mathrm{C}=\mathrm{O}$ bonds of pindone elongate in $\mathrm{P} 1$ and $\mathrm{P} 2$ while $\mathrm{C}-\mathrm{C}$ bonds shrink in length compared to the respective bonds in pindone. Some very small changes also occur in carbon-carbon bonds in rest of the structures as compared to the lengths in pindone.
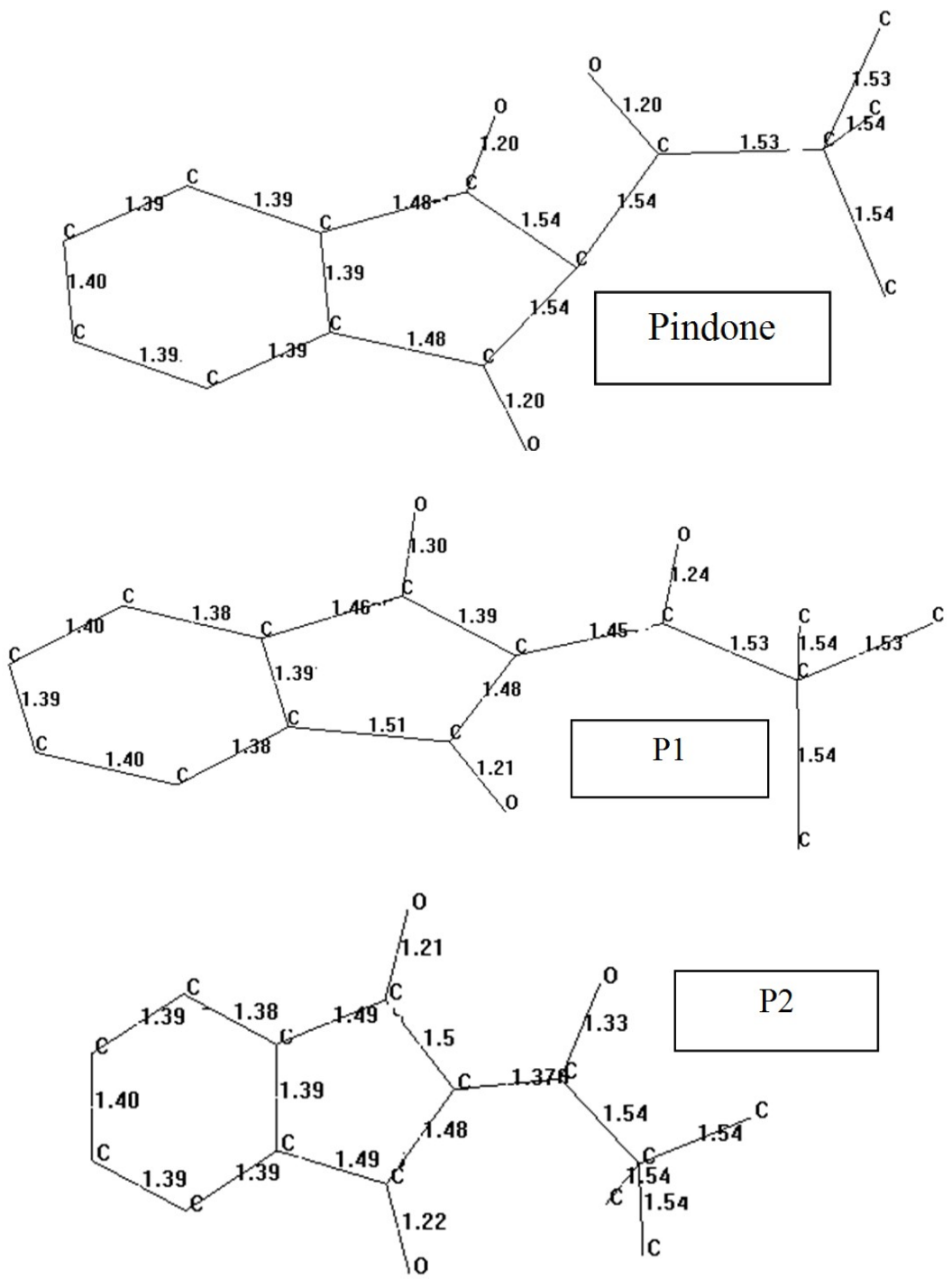

Figure 2. Bond lengths (Á) of the structures considered. 
Figure 3 displays electrostatic charges on the atoms based on electrostatic potential (ESP). The ESP charges are obtained by the program based on a numerical method that generates charges that reproduce the electrostatic potential field from the entire wavefunction [21]. According to the calculated charges, the atoms of the carbonyls linked to the five-membered ring have almost the same charges on the carbon or oxygen atoms. This situation is abolished by enolization process to produce P1. Since in pindone, phenylene moiety almost equally supplies electrons to nearby carbonyls, the carbon or oxygen atoms of each carbonyl group possesses comparable charges. Although exocyclic carbon-carbon double bond in P2 at first sight seems to be symmetrically located to indandioyl carbonyls, in P2 unequal charges arise because enolic oxygen lone pairs delocalize at unequal extents to indandioyl carbonyls due to its cis/trans orientation with respect to the carbonyls mentioned.

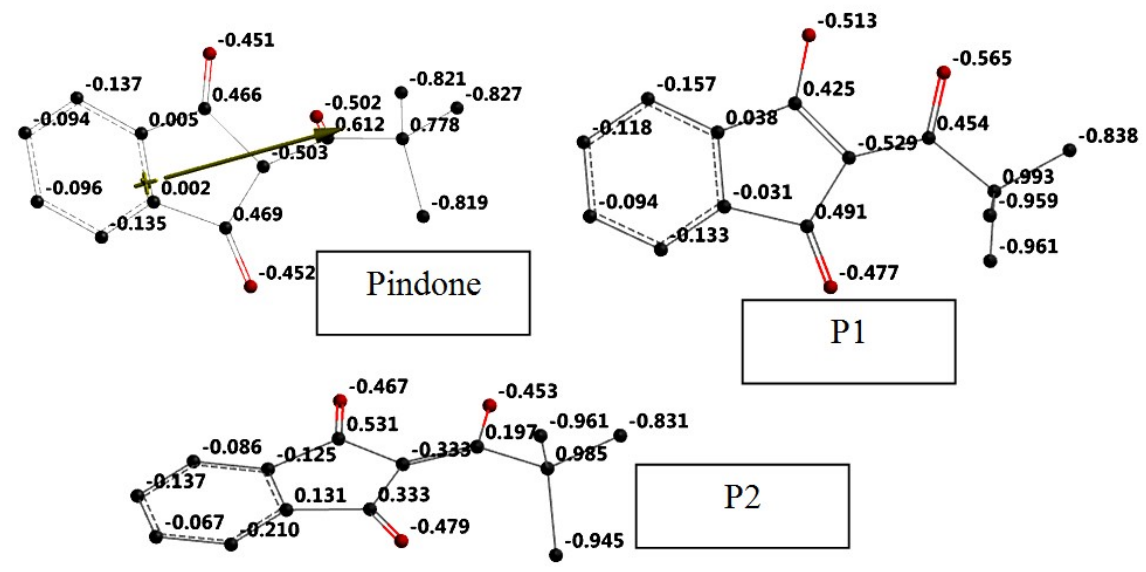

Figure 3. Electrostatic charges (ESP) on atoms of the species considered (Hydrogens are not shown).

Table 2 shows the standard Gibbs free energies and their differences. The data in the table reveal that tautomerization of pindone to yield $\mathrm{P} 1$ is thermodynamically a favorable process in contrast to $\mathrm{P} 2$.

Table 2. Standard Gibbs free energies and their differences.

\begin{tabular}{lcc}
\hline & $\mathrm{G}^{\circ}$ & $\Delta \mathrm{G}^{\circ}$ \\
\hline Pindone & -2015359.681 & 0 \\
P1 & -2015377.908 & -18.2264 \\
$\mathrm{P} 2$ & -2015327.758 & 31.92377 \\
\hline
\end{tabular}

Energies in $\mathrm{kJ} / \mathrm{mol}$. 
Figure 4 shows the calculated IR spectra of the tautomeric species considered. Pindone carbonyl stretchings occur at $1750-1770 \mathrm{~cm}^{-1}$. The skeletal breathing of the aromatic ring happens at $1258 \mathrm{~cm}^{-1}$. In P1 enolic O-H stretching is at $2793 \mathrm{~cm}^{-1}$ and the carbonyl of cyclic part has $\mathrm{C}=\mathrm{O}$ stretching at $1756 \mathrm{~cm}^{-1}$. Whereas the carbonyl of the substituent occurs at $1623 \mathrm{~cm}^{-1}$. As for $\mathrm{P} 2$, the enolic $\mathrm{O}-\mathrm{H}$ stretching is at $3800 \mathrm{~cm}^{-1}$. The ring carbonyl stretches at $1723 \mathrm{~cm}^{-1}$. The peak at $1591 \mathrm{~cm}^{-1}$ stands for enolic $\mathrm{C}=\mathrm{C}$ stretching.
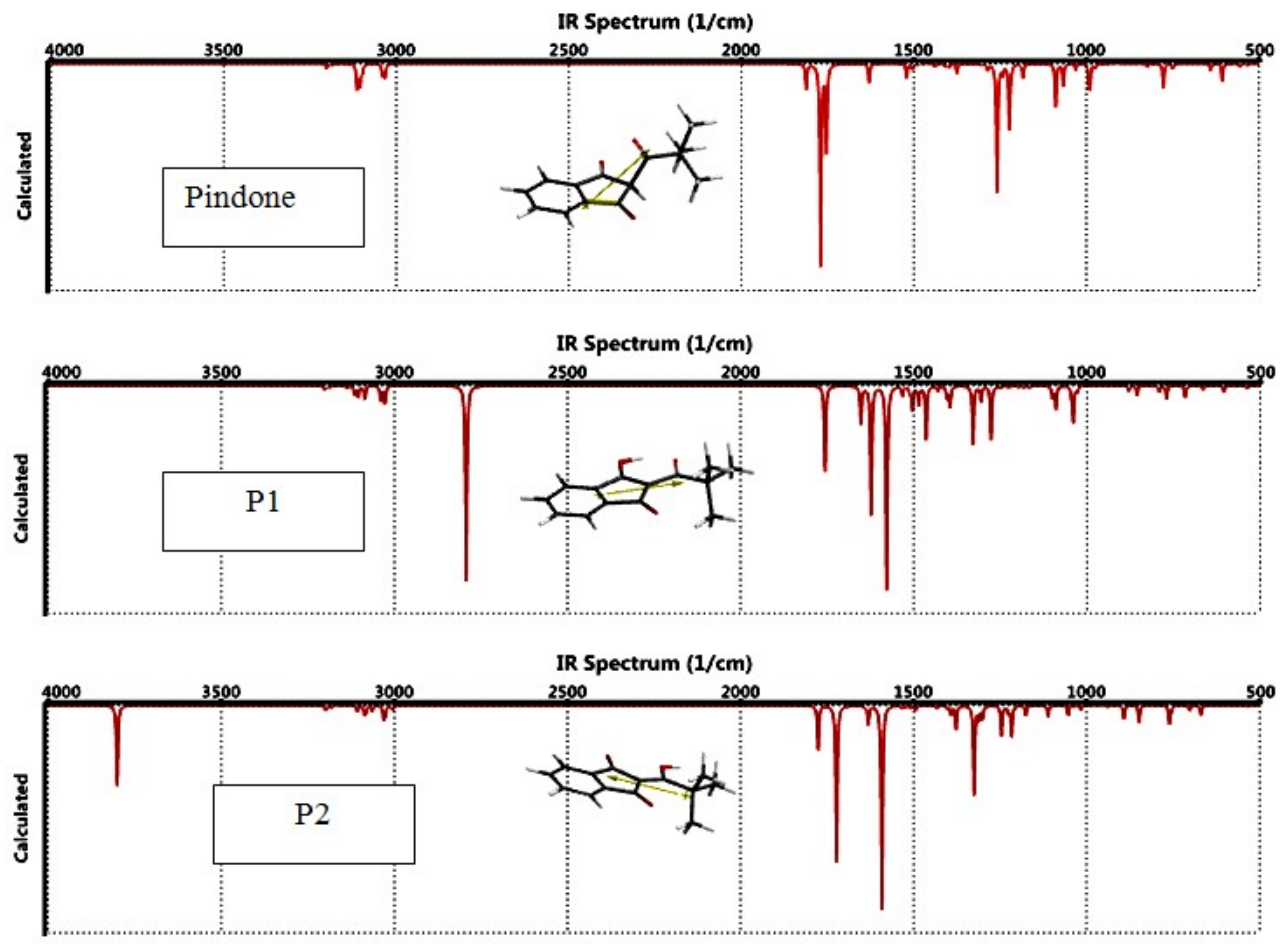

Figure 4. Calculated IR spectra of the species considered.

Table 3 displays some energies of the tautomers considered where E, ZPE and $\mathrm{E}_{\mathrm{c}}$ stand for the total electronic energy, zero point vibrational energy and the corrected total electronic energy, respectively. According to $E_{c}$ values, the electronic stability order follows the sequence of $\mathrm{P} 1>$ pindone $>\mathrm{P} 2$. Note that the order is true for vacuum conditions and hydrogen bonding etc., may change it in other media. 
Table 3. Various energies of the species considered.

\begin{tabular}{lccc}
\hline Structure & $\mathbf{E}$ & ZPE & $\mathbf{E}_{\mathbf{c}}$ \\
\hline Pindone & -2015887.32 & 649.30 & -2015238.02 \\
P1 & -2015908.89 & 651.61 & -2015257.28 \\
P2 & -2015858.57 & 651.77 & -2015206.80 \\
\hline
\end{tabular}

Energies in $\mathrm{kJ} / \mathrm{mol}$.

Figure 5 displays some of the molecular orbital energy levels of the structures. As seen in the figure pindone is characterized with very closely spaced HOMO and NEXTHOMO (NHOMO) energy levels. Tautomer P1 possesses more or less evenly distributed occupied energy levels in contrast to pindone and P2 which have relatively large energy gaps in between the successive groups of energy levels.
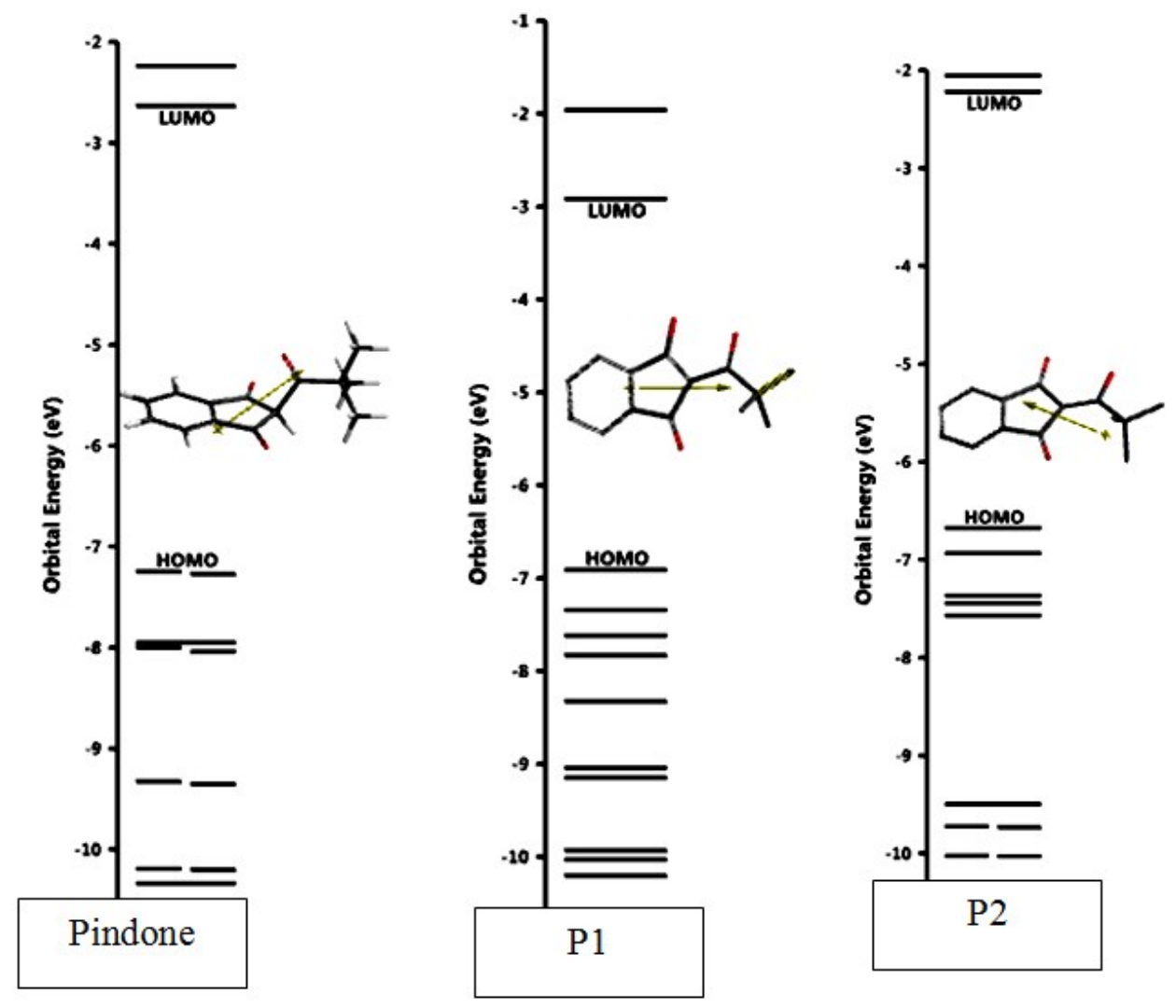

Figure 5. Some of the molecular orbital energy levels of the structures. 
Table 4 shows the HOMO, LUMO energy levels and the interfrontier molecular orbital energy gaps $(\Delta \varepsilon)$, namely the $\varepsilon L U M O-\varepsilon H O M O$ differences. Table 4 indicates that the HOMO, LUMO and $\Delta \varepsilon$ orders are pindone $<\mathrm{P} 1<\mathrm{P} 2$; $\mathrm{P} 1<$ pindone $<\mathrm{P} 2$ and $\mathrm{P} 1<\mathrm{P} 2<$ pindone, respectively.

Table 4. The HOMO, LUMO energies and the interfrontier energy gaps of the species considered.

\begin{tabular}{lccc}
\hline Structure & HOMO & LUMO & $\Delta \varepsilon$ \\
\hline Pindone & -699.07 & -254.41 & 444.66 \\
P1 & -666.64 & -281.50 & 385.14 \\
P2 & -644.18 & -214.53 & 429.65 \\
\hline
\end{tabular}

Energies in $\mathrm{kJ} / \mathrm{mol}$.

Figure 6 shows the calculated UVVIS spectra of the tautomers of which P1 having
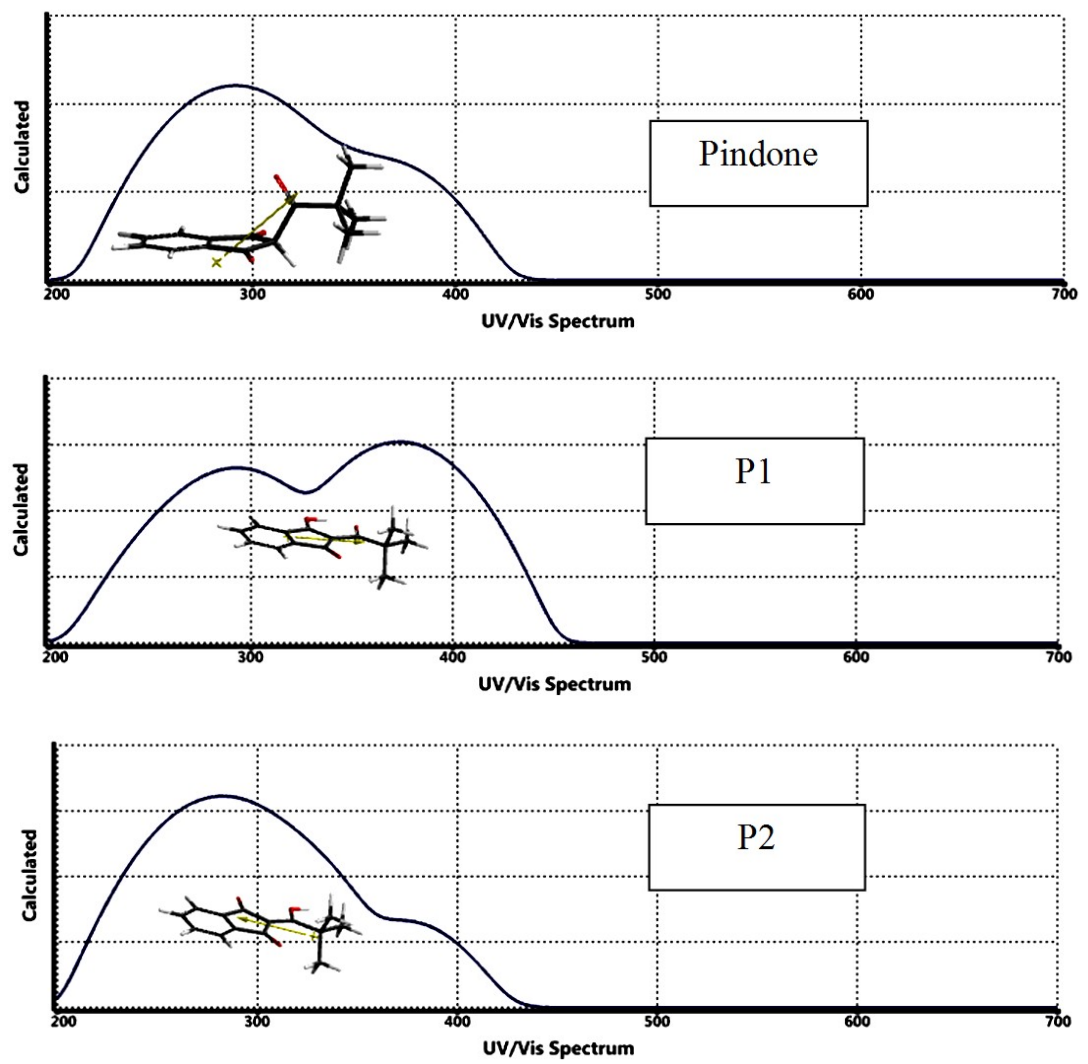

Figure 6. Calculated UV-VIS spectra of the species considered. 
the smallest $\Delta \varepsilon$ value (see Table 4) among the species has a flank somewhat more intensely involved in the visible region. Note that $\mathrm{P} 1$ has a longer extended conjugation path than P2 has. It is known that extended conjugation narrows the interfrontier molecular energy gap causing a bathochromic effect [23].

Figure 7 displays the HOMO and LUMO patterns of the tautomeric species. Pindone has a HOMO constituted mainly by the contribution of atomic orbitals of the substituent. The HOMO of P2 mainly spreads over the pentadione moiety of the structure in contrast to the HOMO of P1 which mainly spreads over the indandionyl part. As for the LUMOs, in pindone and P1 indandionyl moieties supply in to the LUMO. In P2, the enol part also has a great contribution in to the LUMO.
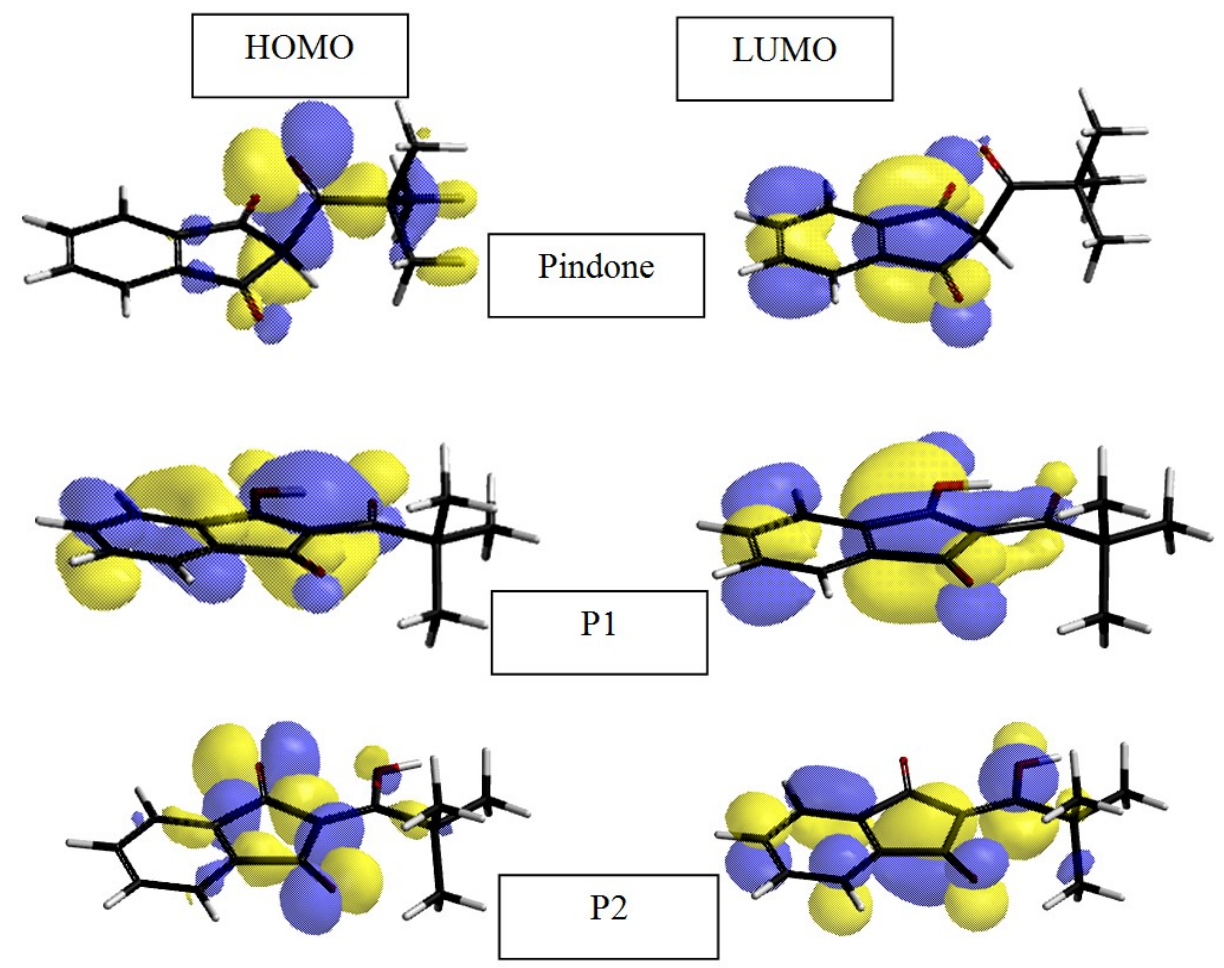

Figure 7. The HOMO and LUMO patterns of the species considered.

Figure 8 shows the electrostatic potential maps of the structures considered. Note that the electrostatic potential provides one measure of molecular charge distribution. This is the energy of interaction of a point positive charge with the nuclei and electrons of a molecule [24]. As seen in the figure, electron rich sites are around the carbonyl 
oxygen atoms. Inductive electron donating effect of tert-butyl group makes carbonyl oxygen of the substituent to have more electronegative potential (darker red region) than the other carbonyls present. In P1 and P2 this carbonyl group is less affected by the mesomeric electron donating effect of enol oxygen atom than the other carbonyl group.
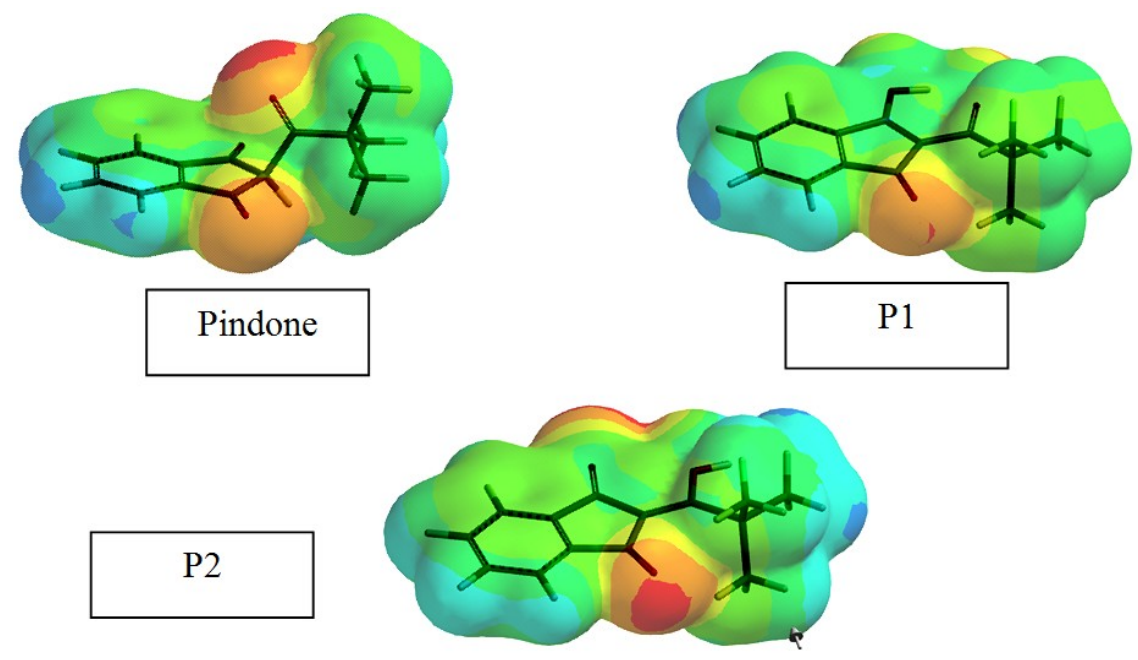

Figure 8. Electrostatic potential maps of the structures considered.

Figure 9 shows the LUMO maps of the species considered. The LUMO map encodes
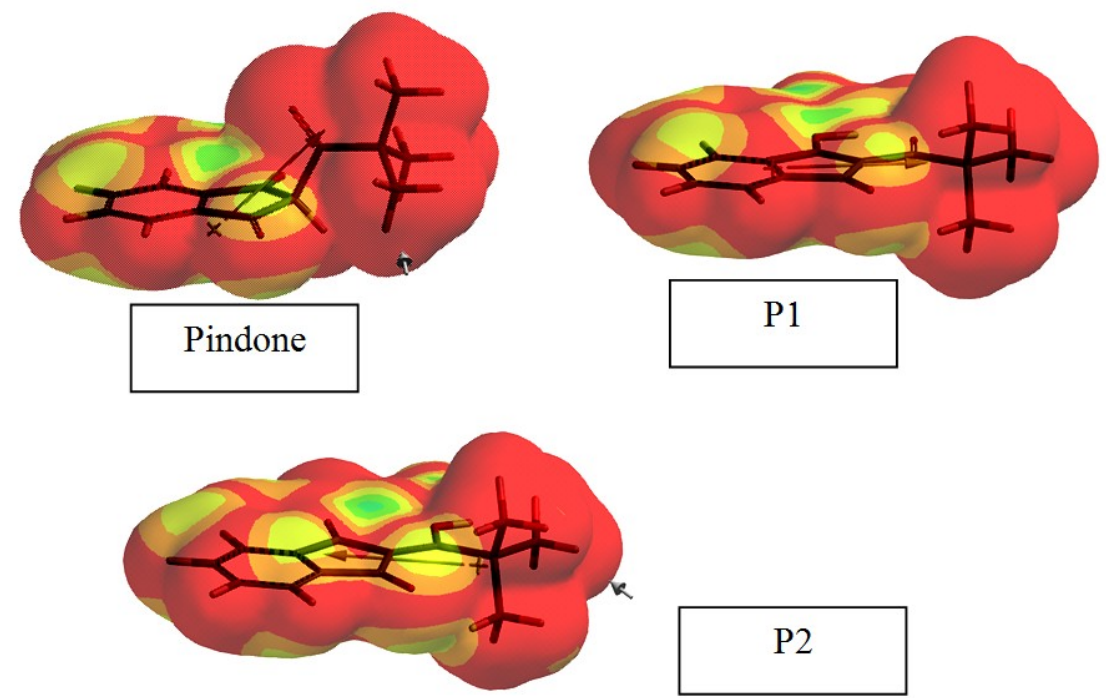

$\mathrm{P} 2$

Figure 9. |LUMO $\mid$ maps of the structures considered. 
the absolute value of the lowest unoccupied molecular orbital (LUMO) onto an electron density surface [24]. This reveals where an electron pair (a nucleophile) is likely to attack. In the figure yellow regions mainly around the carbonyl carbon atoms are susceptible to nucleophilic attacks.

\section{$\operatorname{NICS}(0)$ values}

The calculated data piled in the literature indicate that negative NICS values denote aromaticity (-11.5 for benzene, -11.4 for naphthalene) contrary to positive NICS values which denote antiaromaticity (28.8 for cyclobutadiene) while small NICS values indicate non-aromaticity ( -2.1 for cyclohexane, -1.1 for adamantane). It has been established that NICS may be a useful indicator of aromaticity that usually correlates successfully with the other energetic, structural and magnetic criteria for aromaticity [25-28]. Even it is applicable for saturated systems. For example NICS(0) values of cyclohexane is zero [29]. Resonance energies and magnetic susceptibilities are measures of the overall aromaticity of a polycycle, but do not provide information about the individual rings. In contrast, NICS has been proved to be an effective probe for local aromaticity of individual rings of polycyclic systems.

Table 5 shows the NICS $(0)$ values of the phenylene ring embedded in the species considered. The results indicate the aromaticity order is as pindone $>$ P2 $>$ P1. In pindone the symmetrically located carbonyl groups nearby the phenylene moiety result almost symmetrical charge distribution. In other words, the electron attracting effect of carbonyls is counter balanced. So the electron flow from phenylene moiety towards the carbonyls is minimized to result more complete $6 \pi$ electron sextet for the cyclic conjugation. In the case of $\mathrm{P} 2$, the enol moiety is involved in extended conjugation with the carbonyls but not with phenylene moiety in contrast to P1 in which the extended conjugation spreads over the phenylene ring. Thus in these tautomeric species, depending on the extent of conjugative effects local aromaticity values are dictated.

Table 5. NICS $(0)$ values of the species considered.

\begin{tabular}{ccc}
\hline & Species & \\
\hline Pindone & P1 & P2 \\
-7.7385 & -6.6576 & -7.4242 \\
\hline
\end{tabular}




\section{Conclusion}

The level of DFT calculations presently performed relives that in vacuum conditions a well known rodenticide, pindone, undergoes a 1,3-type keto-enol tautomerism to yield an endocyclic enol (P1). It is more stable electronically and more favorable thermodynamically than the isomeric 1,3-type exocyclic enol as well as pindone itself, although both enols are capable of forming six-membered rings via hydrogen bonding in between the enol $\mathrm{O}-\mathrm{H}$ group and the carbonyl oxygen present on the other end of the conjugative path.

\section{References}

[1] R. Cremlyn, Pesticides; Preparation and Mode of Action, NY: Wiley, 1978.

[2] J. R. Beauregard, T. W. Tusing and R. F. Hanzal, Anticoagulant rodenticide, toxicity and antidotal studies on 2-pivalyl-1,3-indandione (pival), an anticoagulant rodenticide, $J$. Agric. Food Chem. 32 (1955), 124-127. https://doi.org/10.1021/jf60048a002

[3] C. T. Eason and S. E. Jolly, Anticoagulant effects of pindone in the rabbit and Australian Bushtail Possum, Wildlife Research 20(3) (1993), 371-374. https://doi.org/10.1071/WR9930371

[4] G. R. Martin, R. J. Sutherland, I. D. Robertson, D. R. King and P. J. Hood, Assessment of the potential toxicity of a poison for rabbits, pindone (2-pivalyl 1, 3 indandione), to domestic animals, Australian Veterinary Journal 68(7) (1991), 241-243. https://doi.org/10.1111/j.1751-0813.1991.tb03217.x

[5] M. H. Robinson, L. E. Twigg, S. H. Wheeler and G. R. Martin, Effect of the anticoagulant, pindone, on the breeding performance and survival of merino sheep, Ovis aries, Comparative Biochemistry and Physiology Part B: Biochemistry and Molecular Biology 140(3) (2005), 465-73. https://doi.org/10.1016/j.cbpc.2004.11.011

[6] B. Sendra, S. Panadero and A. Gómez-Hens, Determination of pindone in baits by using time-resolved lanthanide-sensitized luminescence and kinetic methodology, Analytical Letters 32(9) (1999), 1835-1846. https://doi.org/10.1080/00032719908542937

[7] I. Csöregh and R. Norrestam, The crystal and molecular structure of 2-pivaloyl-1,3indandione, Acta Cryst. B32 (1976), 2450-2455. https://doi.org/10.1107/S0567740876007954

[8] J. D. Pipkin and V. J. Stella, Tautomerism of phenindione, 2-phenyl-1,3-indandione, in dipolar aprotic/hydrocarbon solvent mixtures, J. Am. Chem. Soc. 10424 (1982), 66726680. https://doi.org/10.1021/ja00388a033 
[9] N. Hocaoğlu, T. Uyar and L. Türker, The syntheses of some novel 2-substituted phenylazo-1,3-indandiones, Dyes and Pigments 12(3) (1990), 187-195.

https://doi.org/10.1016/0143-7208(90)85011-C

[10] V. Enchev, MNDO and AM1 quantum-chemical study of tautomerism of 2-substituted 1,3-lndandiones, Chem. Papers 48 (4) (1994), 219-222.

[11] M. V. Sigalov, Keto-enol tautomerism of phenindione and its derivatives: an NMR and density functional theory (DFT) reinvestigation, J. Phys. Chem. A 119 (2015), 1404-1414. https://doi.org/10.1021/jp512461c

[12] J. J. P. Stewart, Optimization of parameters for semiempirical methods I. Method, $J$. Comput. Chem. 10 (1989), 209-220. https://doi.org/10.1002/jcc.540100208

[13] J. J. P. Stewart, Optimization of parameters for semi empirical methods II. Application, $J$. Comput. Chem. 10 (1989), 221-264. https://doi.org/10.1002/jcc.540100209

[14] A. R. Leach, Molecular Modeling, Essex: Longman, 1997.

[15] P. Fletcher, Practical Methods of Optimization, New York: Wiley, 1990.

[16] W. Kohn and L. Sham, Self-consistent equations including exchange and correlation effects, J. Phys. Rev. 140 (1965), 1133-1138. https://doi.org/10.1103/PhysRev.140.A1133

[17] R. G. Parr and W. Yang, Density Functional Theory of Atoms and Molecules, London: Oxford University Press, 1989.

[18] A. D. Becke, Density-functional exchange-energy approximation with correct asymptotic behavior, Phys. Rev. A 38 (1988), 3098-3100. https://doi.org/10.1103/PhysRevA.38.3098

[19] S. H. Vosko, L. Wilk and M. Nusair, Accurate spin-dependent electron liquid correlation energies for local spin density calculations: a critical analysis, Can. J. Phys. 58 (1980), 1200-1211. https://doi.org/10.1139/p80-159

[20] C. Lee, W. Yang and R. G. Parr, Development of the Colle-Salvetti correlation-energy formula into a functional of the electron density, Phys. Rev. B 37 (1988), 785-789. https://doi.org/10.1103/PhysRevB.37.785

[21] SPARTAN 06, Wavefunction Inc., Irvine CA, USA, 2006.

[22] M. J. Frisch, G. W. Trucks, H. B. Schlegel, G. E. Scuseria, M. A. Robb, J. R. Cheeseman, J. A. Montgomery, Jr., T. Vreven, K. N. Kudin, J. C. Burant, J. M. Millam, S. S. Iyengar, J. Tomasi, V. Barone, B. Mennucci, M. Cossi, G. Scalmani, N. Rega, G. A. Petersson, H. Nakatsuji, M. Hada, M. Ehara, K. Toyota, R. Fukuda, J. Hasegawa, M. Ishida, T. Nakajima, Y. Honda, O. Kitao, H. Nakai, M. Klene, X. Li, J. E. Knox, H. P. Hratchian, J. B. Cross, V. Bakken, C. Adamo, J. Jaramillo, R. Gomperts, R. E. Stratmann, O. Yazyev, 
A. J. Austin, R.Cammi, C. Pomelli, J. W. Ochterski, P. Y. Ayala, K. Morokuma, G. A. Voth, P. Salvador, J. J. Dannenberg, V. G. Zakrzewski, S. Dapprich, A. D. Daniels, M. C. Strain, O. Farkas, D. K. Malick, A. D. Rabuck, K. Raghavachari, J. B. Foresman, J. V. Ortiz, Q. Cui, A. G. Baboul, S. Clifford, J. Cioslowski, B. B. Stefanov, G. Liu, A. Liashenko, P. Piskorz, I. Komaromi, R. L. Martin, D. J. Fox, T. Keith, M. A. Al-Laham, C. Y. Peng, A. Nanayakkara, M. Challacombe, P. M. W. Gill, B. Johnson, W. Chen, M. W. Wong, C. Gonzalez and J. A. Pople, Gaussian, Inc., Wallingford CT, 2004.

[23] I. Fleming, Frontier Orbitals and Organic Chemical Reactions, London: Wiley, 1976.

[24] Spartan, Molecular Modeling in Physical Chemistry, Irvine: Wavefunction Inc., USA, 2005.

[25] H. Jiao and P. R. Schleyer, Aromaticity of pericyclic reaction transition structures: magnetic evidence, J. Phys. Org. Chem. 11 (1998), 655-662.

https://doi.org/10.1002/(SICI)1099-1395(199808/09)11:8/9<655::AID-POC66>3.0.CO;2-U

[26] P. R. Schleyer, B. Kiran, D. V. Simion and T. S. Sorensen, Does $\mathrm{Cr}(\mathrm{CO})_{3}$ complexation reduce the aromaticity of benzene?, J. Am. Chem. Soc. 122 (2000), 510-513. https://doi.org/10.1021/ja9921423

[27] D. Quinonero, C. Garau, A. Frontera, P. Ballaster, A. Costa and P. M. Deya, Quantification of aromaticity in oxocarbons: The problem of the fictitious "nonaromatic" reference system, Chem. Eur. J. 8 (2002), 433-438.

https://doi.org/10.1002/1521-3765(20020118)8:2<433::AID-CHEM433>3.0.CO;2-T

[28] S. Patchkovskii and W. Thiel, Nucleus-independent chemical shifts from semiempirical calculations, J. Mol. Model. 6 (2002), 67-75. https://doi.org/10.1007/PL00010736

[29] F. A. Carey and T. J. Sundberg, Advanced Organic Chemistry A, NY: Kluwer-Plenum, 2000 . 